\title{
ASSISTÊNCIA ESTUDANTIL E FORMAÇÃO DE PROFESSORES NO IFCE: UM ELO POSSÍVEL?
}

\author{
Francisca Rejane Bezerra Andrade \\ Ludimila Façanha Lopes
}

\section{INTRODUÇÃO}

Para que tenhamos compreensão acerca da Política Pública de Educação no Brasil, é necessário que inicialmente façamos o exercício de pensar sobre o que é e a que se propõe uma política pública para que entendamos onde se situa a Política de Educação nesse universo. É importante, portanto, delimitarmos que aqui pensamos a educação como uma política pública social construída e redefinida a partir do movimento social, político, econômico e cultural de uma sociedade cujos interesses pautam-se na lógica de acumulação de riquezas e que dentro desse cenário de disputas e contradições entre os diversos atores envolvidos é que se definem como, para quem e para quê essas políticas irão existir.

Souza (2006), ao tratar acerca de Política Pública, afirma que é necessário pensá-las a partir de inter-relações entre as esferas que envolvem o Estado, a política, a economia e a sociedade como um todo.

Diante disso, é relevante destacarmos o pensamento de Rua (2012) quando define a política pública como sendo o "conjunto de procedimentos formais e informais que expressam relações de poder e que se destinam à resolução pacífica dos conflitos quanto a bens públicos” (RUA, 2012, p. 15). Dentro dessa perspectiva, a autora destaca que nesse processo estão inseridos diversos atores sociais imbuídos de interesses muitas vezes conflitantes e que no processo de construção de consensos entre eles é que as políticas públicas são formuladas e reformuladas constantemente.

Assim, entendendo as políticas públicas como resultado de um processo de busca de consenso entre interesses muitas vezes contraditórios, frutos de uma sociedade capitalista, torna-se necessário que façamos uma breve análise do contexto econômico e social da sociedade brasileira para que possamos compreender os elementos que se inserem no processo de formulação da política educacional brasileira e suas características.

Desse modo, pretendemos aqui traçar algumas reflexões acerca dessa política pública, bem como de seus desdobramentos em torno do ensino superior e seu processo de expansão, que dentre tantos aspectos ressaltamos a proliferação das licenciaturas por meio da obrigatoriedade de oferta nos Institutos Federais e o surgimento da assistência estudantil como elemento facilitador do acesso 
e da permanência, bem como uma possível aliada ao processo de formação dos estudantes por meio de seu potencial educativo.

Nossas discussões, nesse artigo, serão a nível teórico, fundamentadas por meio da pesquisa bibliográfica e documental, dialogando com autores e documentos oficiais que tratam da política de educação, expansão do ensino superior, assistência estudantil e formação de professores nos Institutos Federais, aproximando as reflexões para a realidade do Instituto Federal do Ceará a partir de documentos e publicações da instituição no que tange à assistência estudantil.

No primeiro momento, refletiremos acerca da política educacional no Brasil e o processo de expansão do ensino superior. Em seguida, faremos uma contextualização da formação de professores nos Institutos Federais e da assistência estudantil a partir do Decreto $\mathrm{n}^{\mathbf{0}}$ 7.234/2010 e finalizaremos com a discussão em torno da dimensão educativa da assistência estudantil como um caminho possível na contribuição para a formação de professores no Instituto Federal de Educação, Ciência e Tecnologia do Ceará (IFCE).

\section{A POLÍTICA EDUCACIONAL NO BRASIL E O PROCESSO DE EXPANSÃO DO ENSINO SUPERIOR}

A sociedade brasileira, dentro do contexto econômico e social do capitalismo, tem uma configuração bem peculiar, tendo em vista suas características únicas de uma sociedade marcada pelo forte clientelismo, patrimonialismo, pela centralização do poder e autoritarismo. O Brasil, assim como os demais países latino-americanos tiveram um modo bem específico de desenvolvimento do sistema capitalista, implicando principalmente na utilização da coisa pública em favor dos interesses pessoais de minorias ou grupos políticos que já se encontravam no poder há muito tempo, influenciando sobremaneira a forma de gestação e execução das políticas públicas, em especial da política educacional.

As configurações do pensamento capitalista desde o processo de expansão do capitalismo mercantil, passando pela Revolução Industrial, pelas ideias do liberalismo, fordismokeynesianismo, neoliberalismo/acumulação flexível, ou seja, qual configuração/denominação que o capital passe a ter no sistema globalizado de acumulação, jamais foram homogêneas na sociedade brasileira e isso irá implicar também na forma como o Brasil desenvolveu e desenvolve suas políticas públicas.

Desse modo, consideramos pertinente o pensamento de Frigotto (2010) quando argumenta que: 
A educação e a formação humana terão como sujeito definidor as necessidades, as demandas do processo de acumulação de capital sob as diferentes formas históricas de sociabilidade que assumir. Ou seja, reguladas e subordinadas pela esfera privada, e à sua reprodução. [...] A educação [...] é concebida como uma prática social, uma atividade humana e histórica que se define no conjunto de relações sociais, no embate dos grupos ou classes sociais, sendo ela mesma forma específica de relação social. (FRIGOTTO, 2010, p. 33).

Assim, corroborando também com as concepções teóricas trabalhadas por Behring e Boschetti (2008), não podemos tentar compreender ou até explicar o surgimento e desenrolar das políticas sociais sem o entendimento de que existe uma relação entre políticas sociais, política econômica e luta de classes e que a partir disso, considerando um movimento dialético e de contradições dessa sociedade, o Estado, como instrumento de dominação social, irá direcionar seus esforços na elaboração e condução das políticas públicas, estando aqui incluída a política de educação.

A Educação aparece nos textos constitucionais desde a Constituição de 1824. Porém, segundo Vieira (2007), é a Constituição de 1988 que traz a noção um pouco mais ampliada da educação como um direito em relação às constituições que a antecederam, refletindo o momento de abertura política e de redemocratização no país. O texto constitucional que trata da educação propõe:

[...] a incorporação de sujeitos historicamente excluídos do direito à educação, expressa no princípio ‘da igualdade de condições para o acesso e permanência na escola’ (art. 206, I). [...] a educação como direito público subjetivo [art. 208, $\S 1^{\circ}$ ], o princípio da gestão democrática do ensino público [art. 206, VI], a oferta de ensino noturno regular (art. 208, VI), o ensino fundamental obrigatório e gratuito, inclusive aos que a ele não tiveram acesso em idade própria [art. 208, I], o atendimento educacional especializado aos portadores de deficiências [art. 208, III]. (VIEIRA, 2007, p. 304)

Interessante observar que a Carta Magna de 1988 é a que mais avança em termos de organização dos deveres do Estado diante da educação, imprimindo a ela o caráter de "Constituição Cidadã”. Segundo Vieira (2007),

A Constituição de 1988 mantém a competência privativa da União para 'legislar sobre diretrizes e bases da educação nacional' [art. 22, XXIV] e compartilhada com os Estados, o Distrito Federal e os Municípios para 'proporcionar os meios de acesso à cultura, à educação e à ciência’ [art. 23, V] (VIEIRA, 2007, p. 305).

Nesse contexto, é importante tecermos algumas considerações sobre a Lei de Diretrizes e Bases da Educação Nacional de 1996 (LDB/96) para que entendamos minimamente a configuração atual da política de educação brasileira e seus efeitos sobre o cenário da educação superior no país. 
A partir do que já sinalizamos acerca da relação entre o sistema capitalista e o desenvolvimento de políticas públicas sociais (BEHRING E BOSCHETTI, 2008), é interessante perceber que a LDB/96 traz claramente o seu objetivo na sociedade a partir da lógica de acumulação de riqueza e exploração do trabalho quando diz, em seu artigo $2^{\circ}$, que

a educação, dever da família e do Estado, inspirada nos princípios de liberdade e nos ideais de solidariedade humana, tem por finalidade o pleno desenvolvimento do educando, seu preparo para o exercício da cidadania e sua qualificação para o trabalho [grifo nosso] (BRASIL, 1996).

Outro aspecto importante trazido pelo LDB/96 é a consolidação da educação como mercadoria. É a LDB/96 que traz explicitamente essa abertura para o mercado e traz elementos reguladores desse processo. Na lei diz que a educação será ministrada por meio de princípios, dentre os quais está “a coexistência de instituições públicas e privadas de ensino" (art. $\left.3^{\circ}, \mathrm{V}\right)$. Além disso, determina que:

Art. $7^{\circ}$. O ensino é livre à iniciativa privada, atendidas as seguintes condições: I - cumprimento das normas gerais da educação nacional e do respectivo sistema de ensino; II - autorização de funcionamento e avaliação de qualidade pelo Poder Público; III - capacidade de autofinanciamento, ressalvado o previsto no art. 213 da Constituição Federal (BRASIL, 1996).

Essa coexistência entre o poder público e a iniciativa privada na execução da política de educação irá perpassar todos os níveis de ensino e em cada um deles apresentará diferentes formas de atuação de organizações privadas com fins lucrativos. Essa dimensão mercadológica da educação se torna bem visível quando analisamos a Educação Superior no Brasil e seu processo de expansão nas últimas décadas.

Segundo Lima (2013), se quisermos analisar a expansão da educação superior no Brasil, é preciso que entendamos o papel da Universidade em um país capitalista dependente, cujos processos de desenvolvimento do capitalismo estiveram sempre como condicionantes dessas "mudanças" no sistema educacional brasileiro. Nesse sentido, destaca três principais necessidades do sistema capitalista que estiveram atreladas ao processo de expansão do ensino superior no Brasil: a necessidade de subordinação da ciência à lógica mercantil; a formação de novos campos de lucratividade para o capital e a busca por manter um consenso em torno do projeto neoliberal de sociabilidade.

Diante desses aspectos, torna-se fundamental compreender o papel que o Estado brasileiro assumiu na condução dessa política de expansão da educação superior. Assim, Mancebo, Vale e Martins (2015) argumentam que: 
Se, por um lado, a expansão engendrada nas últimas décadas pode ser percebida como positiva por ampliar o acesso da população ao ensino superior, deve-se atentar para alguns efeitos perversos desse mesmo processo, particularmente no que tange ao perfil dos cursos e das carreiras criados pelas instituições privadas, cuja expansão se dá sob a influência direta de demandas mercadológicas, valendo-se dos interesses da burguesia desse setor em ampliar a valorização de seu capital com a venda de serviços educacionais (MANCEBO; VALE; MARTINS, 2015, p. 33).

O que pretendemos aqui é apontar que o processo de expansão do ensino superior no Brasil está intrinsecamente relacionado com o fortalecimento da educação como mais um mercado no qual o capital pode reproduzir-se. Assim, a educação superior torna-se mais uma mercadoria que pode ser negociada e vendida e que é fortalecida como tal por iniciativas do próprio poder público estatal, como o Programa Universidade para Todos (PROUNI) ${ }^{1}$ e o Fundo de Financiamento Estudantil $(\text { FIES })^{2}$, dentre outros.

No contexto dessa expansão, que se faz principalmente pela ampliação e fortalecimento das Instituições privadas, temos também, em menor escala, o aumento do número de instituições públicas, destacando-se nesse cenário a expansão do ensino superior dentro da Rede Federal de Educação Técnica e Tecnológica, por meio dos Institutos Federais. Estes se espalham em todo o território nacional a partir da Lei 11.892 de 2008, e agregam dentro de seu universo cursos técnicos integrados ao ensino médio, subsequentes ou concomitantes, cursos de graduação tecnológica, bacharelados, engenharias e licenciaturas.

\section{CONTEXTUALIZANDO A FORMAÇÃO DE PROFESSORES NOS INSTITUTOS FEDERAIS}

Iniciamos a reflexão ressaltando que um dos principais pontos a serem discutidos neste tópico é o papel atribuído aos Institutos Federais (IF's) como locus de formação de professores a partir do processo de expansão do ensino superior no Brasil.

A criação dos Institutos Federais, acompanhada por sua expansão pelo território brasileiro, faz parte das políticas de expansão da educação superior, incluindo as políticas específicas voltadas para a formação de professores, iniciadas durante o governo do então presidente Lula. De forma a assegurar essa política, há, na Lei $\mathrm{n}^{\circ} 11.892 / 2008$, em seu art. $7^{\circ}$, a prerrogativa de que os Institutos Federais devem ofertar '[...] cursos de licenciatura, bem como programas

\footnotetext{
${ }^{1}$ O Programa Universidade Para Todos (ProUni) foi criado pela Lei 11.096, de 13 de janeiro de 2005, com o objetivo de oferecer bolsas de estudo em instituições privadas de ensino superior.

${ }^{2}$ O Fundo de Financiamento Estudantil é um programa do Ministério da Educação destinado a financiar a graduação na educação superior de estudantes matriculados em cursos superiores não gratuitos na forma da Lei 10.260/2001.
}

Revista Teias v. 18, n. 50, 2017 (Jul./Set.): Conversas sobre formação de professores, práticas e currículos 
especiais de formação pedagógica, com vistas na formação de professores para a educação básica, sobretudo nas áreas de ciências e matemática, e para a educação profissional" [BRASIL, 2008] (LIMA; SILVA, 2013, p. 16).

Levando em conta os aspectos já discutidos sobre a relação entre políticas públicas e a reprodução da sociabilidade capitalista, questionamo-nos se a inclusão das licenciaturas nos Institutos Federais não seriam também mais um dos elementos que compõem essa teia de relações que contribuem para a manutenção de uma perspectiva educacional que colabore com o consenso entre diversos segmentos sociais da sociedade capitalista. A própria história de criação dessas instituições desde a Escola de Aprendizes Artífices no início do século XX revela a que público se destina e qual o projeto de educação que se pretende para a classe trabalhadora. Nesse sentido, Lustosa e Souza (2015) argumentam que:

Se pensarmos que as Instituições que se transformaram em IF, historicamente, sempre estiveram preocupados em atender a uma demanda de mercado, poderíamos assim dizer que a oferta das licenciaturas estaria de algum modo relacionada com essas exigências. [...]. Por ser um elemento que coopera com essas mudanças educacionais, a formação de professores é um ponto a ser destacado nas reformas educativas, já que os docentes são sujeitos que formam academicamente outros que contribuirão com o processo de reestruturação produtiva, que colaborarão com o capital. Se analisarmos por esse viés, poderíamos entender a formação do docente como fomentadora da educação de cidadãos que irão alimentar o sistema produtivo, a sociedade capitalista, rompendo com o caráter de uma educação emancipadora do sujeito (LUSTOSA; SOUZA, 2015, p. 5).

Mas, quais os discursos do Estado brasileiro que justificam a inclusão de licenciaturas como requisito obrigatório de funcionamento dos Institutos Federais?

Analisando o documento publicado pelo Ministério da Educação Contribuições para o processo de construção dos cursos de licenciatura dos Institutos Federais de Educação, Ciência e Tecnologia, encontramos como justificativa a carência de professores para a educação básica nas áreas de ciências da natureza e matemática evidenciada pelo relatório realizado pelo Conselho Nacional de Educação no ano de 2007, o qual apontou uma necessidade de 272.327 professores dessas áreas.

Nesse mesmo documento, evidencia-se o pensamento que perpassa essa perspectiva de formação de professores nos Institutos Federais quando possui como um de seus objetivos: “formar um professor destinado a atuar na Educação Básica e/ou Profissional, garantindo a construção de sólidas bases profissionais para uma formação docente sintonizada com a flexibilidade exigida pela sociedade atual" (MEC, S/D) 
Assim, percebe-se claramente uma preocupação em atender às demandas da sociedade atual, que tem como uma das principais características esse caráter de flexibilidade e polivalência nas formações profissionais como exigências para a empregabilidade.

No entanto, se enfatizarmos apenas uma visão fatalista em torno desse projeto de formação, estaríamos desconsiderando o movimento que contraditoriamente pode se estruturar por meios de propostas fomentadoras de reflexão a esse sistema e de uma formação realmente crítica. É nesse sentido que acreditamos que nos espaços institucionais possam vir a nascer iniciativas educacionais que corroborem com essa perspectiva e que de algum modo venham a contribuir para o estímulo a um pensamento crítico voltado aos mais diversos aspectos sociais.

Essas iniciativas, gestadas dentro dos próprios Institutos, podem ser as mais diversas possíveis e provocadas pelos mais diferentes atores que compõem o universo educacional dessas instituições. Nesse sentido, apontamos aqui a potencialidade da assistência estudantil como uma dessas alternativas de construção de contribuições para essa formação docente, tendo em vista o importante papel desempenhado pela mesma na democratização do acesso e permanência desses estudantes, bem como sua proximidade com os mesmos e também o caráter educativo que possui.

\section{A ASSISTÊNCIA ESTUDANTIL E SUA DIMENSÃO EDUCATIVA: NEM SOMENTE DE AUXÍLIOS SE VIVE O ESTUDANTE}

A assistência estudantil formaliza sua participação nas instituições públicas de ensino superior a partir do Decreto 7.234, de 19 de julho de 2010, o qual dispõe sobre o Programa Nacional de Assistência Estudantil (PNAES). Este Programa tem como objetivo principal "ampliar as condições de permanência dos jovens na educação superior pública federal" $\left(\operatorname{art} .1^{\circ}\right)$.

Dentre as demais determinações advindas com o referido Programa, temos que as ações pertinentes à assistência estudantil deverão estar articuladas com as atividades de ensino, pesquisa e extensão, tornando-se evidente, conforme salienta Nascimento (2013), que a Assistência Estudantil deve ultrapassar o viés marcante de ações de repasse financeiro para uma política na qual possam ser formuladas ações que contribuam para o atendimento dos estudantes em seus diversos aspectos, oferecendo possibilidades de superação de possíveis obstáculos no seu trajeto acadêmico.

Nessa perspectiva, insere-se a assistência estudantil como uma aliada ao percurso formativo do aluno nas instituições de ensino superior. Assim, suas ações e serviços devem ser direcionados de modo a considerar o discente como parte integrante de uma sociabilidade macroestruturada sob a qual se refletem consequências de sua condição social e econômica, as quais devem ser 
minimamente superadas de modo a não interferir na continuidade dos estudos, nem no seu desempenho na instituição.

Assim, imprime-se a ideia da importância desse acompanhamento aos estudantes por parte dos profissionais que compõem a equipe de assistência estudantil. Exige-se, portanto, que está compreenda o universo de vivências do estudante (social, cultural, econômica, regional, etc.) de forma a tornar possível compreendê-lo em seu contexto mais amplo e que, desse modo, melhor contribua para o seu processo de formação.

E como então relacionar assistência estudantil e formação de professores? Onde esses dois elementos se encontram nesse cenário educacional?

\section{REFLEXÕES ACERCA DAS POSSIBILIDADES DE PARTICIPAÇÃO DA ASSISTÊNCIA ESTUDANTIL NA FORMAÇÃO DE PROFESSORES NO IFCE}

Ora, se pensarmos que tanto a obrigatoriedade das licenciaturas nos IF's a partir da Lei 11.892/2008, como o PNAES são frutos, dentre outros aspectos, do movimento de expansão do ensino superior e que ambos se relacionam cotidianamente na mesma instituição, eis aí o primeiro encontro.

Mas, como discutir a participação da assistência estudantil no processo de formação de professores nos Institutos Federais? Como podemos refletir sobre isso?

Primeiramente, vamos pensar no elemento-chave que irá fundamentar algumas de nossas discussões e reflexões: tendo como pressuposto que todos os profissionais de uma instituição de ensino (docentes, técnicos, etc.) são agentes no processo educativo dos discentes, e que essencialmente a estrutura organizacional da equipe de assistência estudantil pressupõe um trabalho multiprofissional junto aos estudantes de modo a propiciar um espaço que contribua no seu desempenho acadêmico, temos, pois, a suposição de que essa equipe possa vir a contribuir, de alguma forma, no processo de formação dos discentes, no caso mais específico, daqueles que estão nas licenciaturas.

Mas, a assistência estudantil não deveria apenas se preocupar com o acesso, com a garantia condições financeiras de permanência e com o êxito do aluno por meio da conclusão do curso no período regular? Isso é o que se revela no discurso muitas vezes reproduzido na rotina institucional do IFCE, por exemplo. Contudo, quando analisamos minimamente a estrutura da equipe, suas ações em conjunto, seus referenciais de atuação e o potencial socioeducativo que possui, vislumbramos 
que se pode ir além do mero repasse financeiro ou de execução de serviços fragmentados e focalizados.

A assistência estudantil ao promover condições de permanência e êxito, pode desenvolver também ações de cunho educativo complementar que contribuam no processo de formação dos estudantes, principalmente daqueles que estão sendo formados professores da educação básica.

Essa potencialidade da dimensão educativa pode ser visualizada através do documento "referenciais de atuação dos profissionais da assistência estudantil" elaborado por assistentes sociais, psicólogos, nutricionistas e enfermeiros que fazem parte da composição funcional da assistência estudantil no IFCE.

Preparamos um quadro com os principais aspectos que direcionam a prática desses profissionais na assistência estudantil para uma perspectiva educativa de forma que possamos melhor visualizar essa dimensão em cada uma das categorias.

QUADRO 1. REFERENCIAIS DE ATUAÇÃO DOS PROFISSIONAIS DA ASSISTÊNCIA ESTUDANTIL NO IFCE

\begin{tabular}{|c|c|c|c|}
\hline $\begin{array}{l}\text { ASSISTENTES } \\
\text { SOCIAIS }\end{array}$ & PSICÓLOGOS & NUTRICIONISTAS & ENFERMEIRO \\
\hline $\begin{array}{l}\text {-A atuação do } \\
\text { assistente social visa a } \\
\text { ampliação das } \\
\text { condições de acesso e } \\
\text { de permanência, com } \\
\text { enfoque numa } \\
\text { formação crítica e } \\
\text { autônoma, para além } \\
\text { de uma formação } \\
\text { meramente tecnicista e } \\
\text { pautada nos ditames } \\
\text { do capital; } \\
\text {-Ações de caráter } \\
\text { coletivo: formação de } \\
\text { grupos, reuniões, } \\
\text { encontros, seminários, } \\
\text { oficinas para os alunos } \\
\text { e técnicos, campanhas, } \\
\text { confecção de materiais } \\
\text { educativos, } \\
\text { mobilização e } \\
\text { organização social e } \\
\text { política, apoio à } \\
\text { constituição das } \\
\text { entidades estudantis; }\end{array}$ & $\begin{array}{l}\text {-Apoiar o (a) professor (a) e } \\
\text { demais servidores no trabalho } \\
\text { com a heterogeneidade de } \\
\text { discentes; } \\
\text {-Fazer parte da equipe } \\
\text { multiprofissional que envolve } \\
\text { o processo de ensino e } \\
\text { aprendizagem; } \\
\text {-Auxiliar no processo de } \\
\text { inclusão e valorização da } \\
\text { diversidade; } \\
\text {-Propiciar condições para que } \\
\text { o (a) discente expresse sua } \\
\text { autonomia e consciência } \\
\text { crítica por meio da } \\
\text { participação ativa na vida } \\
\text { acadêmica, contribuindo para } \\
\text { uma formação cidadã; } \\
\text {-Propiciar aos discentes } \\
\text { espaços de reflexão e diálogo } \\
\text { sobre as temáticas } \\
\text { demandadas pelos diversos } \\
\text { atores que compõem a } \\
\text { comunidade acadêmica; }\end{array}$ & $\begin{array}{l}\text {-Propor e realizar } \\
\text { ações de educação } \\
\text { alimentar e } \\
\text { nutricional (oficinas, } \\
\text { palestras, elaboração } \\
\text { e exposição de } \\
\text { material educativo) } \\
\text { para a comunidade } \\
\text { escolar; } \\
\text {-Interagir com a } \\
\text { equipe } \\
\text { multiprofissional da } \\
\text { saúde, objetivando a } \\
\text { realização de } \\
\text { atividades de } \\
\text { promoção da saúde e } \\
\text { prevenção de } \\
\text { doenças de forma } \\
\text { interdisciplinar. }\end{array}$ & $\begin{array}{l}\text {-Promoção da saúde } \\
\text { com foco na } \\
\text { educação em saúde; } \\
\text {-Contribuir para o } \\
\text { desenvolvimento } \\
\text { integral do discente; } \\
\text {-Colaborar no } \\
\text { mapeamento da } \\
\text { realidade } \\
\text { socioeconômica, } \\
\text { acadêmica e de } \\
\text { saúde dos discentes; } \\
\text {-Atuar na } \\
\text { prevenção, } \\
\text { promoção, } \\
\text { tratamento e } \\
\text { vigilância à saúde } \\
\text { de forma individual } \\
\text { e coletiva, } \\
\text { colaborando com o } \\
\text { processo de ensino- } \\
\text { aprendizagem; } \\
\text {-Desenvolver } \\
\text { atividades de }\end{array}$ \\
\hline
\end{tabular}




\begin{tabular}{|l|l|l|l|}
\hline $\begin{array}{l}\text {-Ações de qualificação } \\
\text { profissional, } \\
\text { capacitação, pesquisa } \\
\text { e extensão: promoção } \\
\text { de grupos de estudos e }\end{array}$ & $\begin{array}{l}\text {-Fomentar momentos de } \\
\text { expressões artísticas, culturais } \\
\text { pesquisas na área } \\
\text { social e temas afins. }\end{array}$ & $\begin{array}{l}\text { acadêmica, propiciando as } \\
\text { interrelações e a circulação da } \\
\text { palavra nas suas mais } \\
\text { diferentes manifestações; }\end{array}$ & $\begin{array}{l}\text { educa } \\
\text { para a adoção de } \\
\text { hábitos saudáveis, } \\
\text { visando à melhoria } \\
\text { da qualidade de } \\
\text { vida e promoção da } \\
\text { saúde da } \\
\text { comunidade } \\
\text { acadêmica. }\end{array}$ \\
& $\begin{array}{l}\text {-Estimular a criatividade e a } \\
\text { iniciativa dos discentes para a } \\
\text { criação de grupos autogeridos } \\
\text { que trabalhem temáticas por } \\
\text { ele definidas. }\end{array}$ & \\
\hline
\end{tabular}

Fonte: Referenciais de atuação dos profissionais da Assistência Estudantil (vol.1), publicado pela Diretoria de Assuntos Estudantis do IFCE em 2016. Elaboração própria, 2017.

Considerando o direcionamento das ações profissionais apontadas no quadro 1, podemos perceber uma clara preocupação em transcender a dimensão meramente de repasse financeiro atribuída corriqueiramente à assistência estudantil ao tratá-la apenas sob a ótica de concessão de auxílios. Esses aspectos aqui ressaltados cruzam com a proposta de formação de professores nos Institutos Federais, principalmente no que tange à sugestão de estrutura curricular proposta pelo documento "Contribuições para o processo de construção dos cursos de licenciatura dos Institutos Federais de Educação, Ciência e Tecnologia”, publicado pelo Ministério da Educação. Esse documento prevê que,

A proposta de Cursos de Licenciaturas dos IF's busca, baseada na transversalidade dos saberes, estabelecer uma estruturação curricular em Núcleos de Formação a partir dos conhecimentos comuns e específicos das áreas de conhecimento e das habilitações, do conhecimento pedagógico e de conhecimentos complementares (MEC, S/D).

Nessa proposta de núcleos apresentada pelo documento em análise, acreditamos ser possível estabelecer elos com a assistência estudantil a partir do núcleo complementar, o qual propõe:

Desenvolver atividades que possibilitem o exercício da habilitação, numa perspectiva interdisciplinar e integradora, por meio do enriquecimento da formação do cursista com conhecimentos das áreas correlatas, bem como com atividades acadêmico-científico-culturais que possam contribuir para que o docente venha a tornar-se um pesquisador de sua própria prática [grifos nossos] (MEC, S/D).

Desse modo, vislumbramos uma possibilidade de a assistência estudantil transcender o forte aspecto financeiro e fortalecer ações que contribuam para a formação dos estudantes numa dimensão mais dialógica e educativa. O potencial educativo e reflexivo que a equipe de assistência estudantil possui, pode e deve ser explorado de modo a colaborar com a formação mais crítica de 
professores numa instituição historicamente tecnicista e ligada à formação de trabalhadores para o mercado de trabalho, atendendo, muitas vezes, aos interesses e às exigências do sistema capitalista.

Apontamos, aqui, como um dos possíveis caminhos para a contribuição da assistência estudantil para essa formação crítica na formação de professores no Instituto Federal do Ceará (IFCE): o entrecruzamento de atividades socioeducativas multidisciplinares fomentadas pelos profissionais integrantes da equipe de assistência estudantil em parceria com as atividades de ensino e/ou pesquisa e/ou extensão desenvolvidas pelos docentes das licenciaturas, respeitando as diretrizes estabelecidas pela matriz curricular de cada curso e levando em consideração os referenciais de atuação de cada profissional que, em conjunto, formariam uma teia de reflexões envolvendo diversos temas transversais a serem trabalhados com os estudantes que se formarão professores.

Obviamente que, numa instituição historicamente tecnicista e preocupada com a formação para o mercado de trabalho, construir uma proposta de atuação que transcenda o projeto hegemônico de educação estabelecido pelo sistema capitalista, traz embates e desafios políticos no cotidiano institucional aos profissionais e professores para a consolidação dessa proposta. Apesar disso, vislumbramos a possibilidade de serem criadas mediações no sentido de promoção de uma educação mais crítica e reflexiva para os licenciados que estão sendo formados no IFCE.

\section{CONSIDERAÇÕES FINAIS}

A partir das reflexões aqui traçadas, foi possível apreender que a educação é política pública nascida dentro de um contexto de embates de interesses de diversos atores envolvidos nesse cenário de disputas e que não pode ser compreendida sem que entendamos a totalidade do contexto social, econômico e cultural no qual ela nasce. Esse contexto é o de um sistema mundial que influencia sobremaneira a forma de organização social que os países vão construir, que é o sistema capitalista. Ressalvada as peculiaridades de cada nação, de cada povo e de cada cultura, esse sistema tomará formas também peculiares, mas sem se distanciar de sua essência que é a acumulação de riquezas por meio da exploração do trabalho.

A educação, assim como a organização do Estado e de suas ações através das políticas públicas, estão ligados a esse modelo de sociabilidade, buscando construir consensos em torno desse projeto socioeconômico.

Não diferente está situado o processo de expansão do ensino superior, no qual pudemos visualizar a forte presença do setor privado e da lógica de mercantilização desse nível de ensino, 
reforçando o pensamento de uma educação que não é para todos e sim para quem pode comprá-la, trazendo uma falsa ideia de democratização do ensino superior e de possibilidade de ascensão social da classe trabalhadora sem refletir sobre a própria estrutura que o sistema visa manter.

Além disso, dentro desse cenário foi possível identificar a coexistência de dois elementos que são frutos desse processo de expansão, mas no âmbito das instituições públicas os quais podem se entrecruzar, mas que, muitas vezes, ambos passam desapercebidos um ao outro e que buscamos aqui minimamente relacioná-los, quais sejam: a assistência estudantil e a formação de professores nos Institutos Federais.

Infelizmente ainda são ínfimas as discussões que giram em torno da dimensão educativa da assistência estudantil e sua potencialidade em participar da proposta de formação de professores numa instituição historicamente marcada pelo atendimento às demandas impostas pelo sistema capitalista de qualificação da força de trabalho, a qual não é interessante, para o sistema, ser formada em sua totalidade e estimulado o senso crítico e vivências sociais que possibilitem esse exercício reflexivo de sua condição e de sua existência.

Por fim, apontamos um caminho possível de inter-relações entre a dimensão educativa e a formação de professores no Instituto Federal do Ceará a ser pensado e refletido de modo que possamos construir mais diálogos em torno dessa questão.

\section{REFERÊNCIAS}

BRASIL. Lei 9.394, de 20 de dezembro de 1996. Estabelece as diretrizes e bases da educação nacional. Diário Oficial da União. Brasília: Poder Legislativo, 23 dez. 1996, sec. I, n. 248, p. 27.833.

PNAES.

Decreto 7.234, de 19 de julho de 2010. Dispõe sobre o Programa Nacional de Assistência Estudantil -

BRASIL. Constituição (1988). Constituição da República Federativa do Brasil. Diário Oficial da União. Brasília: Congresso Nacional, 05 out. 1988. Anexo.

Lei 11.892, de 29 de dezembro de 2008. Institui a Rede Federal de Educação Profissional, Científica e Tecnológica, cria os Institutos Federais de Educação, Ciência e Tecnologia, e dá outras providências.

- Ministério da Educação. Contribuições para o processo de construção dos cursos de licenciatura dos institutos federais. Brasília, DF, S/D. Disponível em http://portal.mec.gov.br/dmdocuments/licenciatura 05.pdf

BEHRING, Elaine; BOSCHETTI, Ivanete. Política social: fundamentos e história. São Paulo: Cortez, 2008.

FRIGOTTO, Gaudêncio. Educação e a crise do capitalismo real. São Paulo: Cortez, 2010.

INSTITUTO FEDERAL DO CEARÁ. Diretoria de Assuntos Estudantil. Referenciais de atuação dos profissionais de assistência estudantil (vol.1). Fortaleza: IFCE, 2016.

LIMA, Fernanda Bartoly Gonçalves de Lima; SILVA, Kátia Augusta Curado Pinheiro. A concepção de formação de professores nos institutos federais: um estudo dos documentos oficiais. Revista da Faculdade de Educação.

vol. 20, ano 11, n. 2, p. 15-33, jul./dez. 2013.

Revista Teias v. 18, n. 50, 2017 (Jul./Set.): Conversas sobre formação de professores, práticas e currículos 
LIMA, Katia. Expansão da educação superior brasileira na primeira década do novo século. In: PEREIRA, Larissa Dahmer; ALMEIDA, Ney Luiz T. (Org.). Serviço social e educação. Rio de Janeiro: Lumen, 2013, p. 11-31.

LUSTOSA, Wigna Eriony A. Morais; SOUZA, Francisca C. Silva. As licenciaturas nos Institutos Federais: a formação de professores ofertadas por instituições de educação profissional. Anais do III Colóquio nacional / Eixo temático III - Formação de professores para a educação profissional. ISSN: 2358-1190. 2015.

MANCEBO, Deise; VALE, Andréa Araújo; MARTINS, Tânia Barbosa. Políticas de expansão da educação superior no Brasil 1995-2010. Revista brasileira de educação, vol. 20, n. 60, jan. /mar. 2015.

NASCIMENTO, Ana P. Leite. Assistência estudantil e projeto ético-político do serviço social: democratizar acesso ou permanência? Revista da Faculdade José Augusto Vieira. Ano VI, n. 8, p. 379-399, set. 2013.

RUA, Maria G. Políticas Públicas. 2. ed. Florianópolis: Departamento de Ciências da Administração/UFSC, 2012.

SOUZA, Celina. Políticas públicas: uma revisão de literatura. Sociologias. Porto Alegre, ano 8, n.16, p. 20-45, jul. /dez. 2006.

VIEIRA, Sofia Lerche. A educação nas constituições brasileiras: texto e contexto. Revista est. pedag. Brasília, v. 88, n. 219, p. 291-309, maio/ago. 2007.

\section{RESUMO}

Neste artigo, objetivamos refletir sobre a possível relação entre a assistência estudantil e a formação de professores no Instituto Federal de Educação, Ciência e Tecnologia do Ceará, considerando uma dimensão educativa articulada entre esses dois elementos. Para tanto, realizamos uma discussão teórica, utilizando a pesquisa bibliográfica e documental. Após as reflexões, concluímos que a assistência estudantil possui uma dimensão educativa que pode e deve ser explorada de modo a contribuir para a formação de professores que se processa no Instituto Federal de Educação, Ciência e Tecnologia do Ceará (IFCE), mas que ainda são muito incipientes as discussões em torno dessa temática.

Palavras-chave: Educação. Assistência Estudantil. Formação de Professores.

\section{STUDENT ASSISTANCE AND TRAINING OF TEACHERS AT THE IFCE: A POSSIBLE CONNECTION? ABSTRACT}

In this article, we reflect on the possible relationship between the student assistance and the training of teachers at the Instituto Federal de Educação, Ciência e Tecnologia do Ceará, considering an educational dimension articulated between these two elements. To this end, we conducted a theoretical discussion, using the bibliographical research and documentary. After the reflections, we conclude that the student assistance has an educational dimension that can and should be explored in order to contribute to teacher training that takes place at the Instituto Federal de Educação, Ciência e Tecnologia do Ceará (IFCE), but they are still very incipient discussions around this theme.

Keywords: Education. Student Assistance. Training of Teachers.

\section{ASISTENCIA A LOS ESTUDIANTES Y FORMACIÓN DE PROFESORES EN IFCE: ¿UNA CONEXIÓN POSIBLE? RESUMEN}

En este artículo, tenemos como objetivo reflexionar acerca de la posible relación entre la asistencia a los estudiantes y la formación de profesores en el Instituto Federal de Educación, Ciencia y Tecnología de Ceará, considerando una dimensión educativa articulada entre esos dos elementos. Para ello, realizamos una discusión teórica, utilizando la investigación bibliográfica y documental. Después de las reflexiones, concluimos que la asistencia a los estudiantes tiene una dimensión educativa que puede y debe ser explorada de modo a contribuir a la formación de profesores que se procesa en el Instituto Federal de Educación, Ciencia y Tecnología de Ceará (IFCE), pero que todavía son Muy incipientes las discusiones en torno a esta temática.

Palabras clave: Educación. Asistencia a los Estudiantes. Formación de Profesores. 